The paper includes useful tables giving the pressure and the density at different heights, the variation of temperature on surfaces of equal pressure, and the temperatures in different quadrants of cyclones and anticyclones.

It is full of interest, and stands as an example of the "thorough" policy of Prof. Hann, to whom, indeed, it would not do discredit.

E. GOLD.

\section{THE GULF STREAM DRIFT AND THE \\ WEATHER OF THE BRITISH ISLES}

A LTHOUGH it has been known for very many years that the climate of these islands and of northern Europe generally is far milder than it would otherwise have been owing to a large body of warm water flowing past its shores from the south-west, it is only within recent years that attempts have been made to trace any detailed connection between the state of the Gulf Stream Drift ${ }^{1}$ and the weather.

Now that systematic hydrographic observations have been accumulating for a number of years it is becoming possible to attack seriously this interesting problem, and the results so far obtained certainly look promising.

The immediate causes of the weather in the British Isles are undoubtedly to be sought in the various atmospheric disturbances which arrive from the Atlantic, but there can be no doubt that another very important factor to be considered is the temperature of the adjacent seas. This is influenced by the Gulf Stream Drift.

The problem is, however, complicated by the fact that there is some doubt as to whether the Gulf Stream Drift may not be a direct result of the atmospheric circulation in the huge cyclonic system which rests over the North Atlantic, with its centre at Iceland.

$\mathrm{Be}$ that as it may, there is undoubtedly a very intimate connection between the oceanic and atmospheric circulations in the North Atlantic region, so that if the atmospheric circulation becomes more vigorous, the Gulf Stream Drift moves faster, and vice versâ. This is well shown in a paper by Meinardus in the Meteorologische Zeitschrift, xxii., 398 , r905. Such a connection was, however, to be expected, not only if the Gulf Stream Drift were directly due to the atmospheric circulation, but also if, as seems more probable, both were due to the same cause, namely, the excessive cooling at the poles of the earth, coupled with the rotation of the earth about its axis. On this view both the oceanic and atmospheric circulations are of the nature of convection currents, and primarily due to the same cause, but in the course of ages these two distinct circulations have so adjusted themselves that any change in the one rapidly causes a corresponding change in the other.

It seems probable, therefore, that the Gulf Stream Drift, owing to its inertia and its great heat capacity, should have a similar effect to that of the flywheel of an engine, and tend to obliterate the disturbances due to the more unstable and variable atmospheric circulation. In this case the Gulf Stream Drift should have a very considerable regulating influence on the general type of weather prevailing in the British Isles.

Let us consider the probable influence on the temperature and on the rainfall. In the winter the temperature of the Gulf Stream Drift is higher than that of the land, while in the summer it is lower.

1 The warm water flowing round the British Isles to Scandinava used to be called the Gulf Stream. The Gulf Stream proper is now considered not to extend further east than Newfoundland, while its fan-like extension which crosses over to Europe is known as the Gulf Stream Drift.
Consequently during the winter time the winds blowing from the Atlantic tend to raise the temperature of the land, while in the summer they tend to lower it, and it is clear that variations in the temperature of the Drift must be expected to affect the temperature of the winds blowing over it, and consequently the temperature on land as well. Such effects on the land temperature will probably be far more important in the winter than in the summer, owing to the relatively greater power of the solar radiation during the summer.

The effect on the rainfall will be equally marked, for the amount of moisture carried by the winds and available for precipitation as rain depends largely upon the temperature of the sea over which they have blown. The warmer the sea the more moisture is taken up and the more precipitation may be expected on the neighbouring land.

In this way, for instance, it is possible to account for the low rainfall last year in the western parts of Great Britain and Ireland-parts which are usually very wet-for during 1909 the temperature of the Gulf Stream Drift was below the normal, and hence the winds blowing from it were not so heavily charged with moisture as usual.

The somewhat lower land temperature seems to have just about compensated for this by the time the winds reached the east of Great Britain, so that the rain fell there instead of in the west. The result of this was an abnormally high rainfall in the east, and with the low one in the west the rainfall over the British Isles as a whole was exactly equal to the average.

It will be very interesting to see if this is what may be generally expected in years when the Gulf Stream Drift is weaker than usual.

There is clearly a possibility of being able to predict the general character of the weather in these islands several months in advance from the results of hydrographic observations. It is, of course, a very complex question, and at present one cannot be too confident, but I am certainly of the opinion that such predictions will be possible.

In another place I have thrown out the suggestion that, as the February hydrographic observations made in the Irish Sea this year were almost identical with those of last year, there was some probability that the weather during igio would be somewhat similar to that of last year. It was never expected that the suggestion would attract the attention it has done, but it is interesting to note that the May hydrographic observations are also very similar to those of last year-if anything, even less favourable.

H. Bassett.

\section{PROF. G. V. SCHIAPARELLI.}

PROF: SCHIAPARELLI, whose death we briefly announced last week, for many years occupied a prominent position in the world of science. Half a century has passed since he began his career as second assistant in the Brera Observatory of Milan, and nearly as many since he was elected to fill the position of director. In that position he exhibited much energy, and increased the reputation of the observatory. But his greatest success came to him early, and though he worked long and diligently, giving evidence of patient industry and practical skill as an observer, he will be remembered mainly for having satisfactorily established the connection between meteors and comets. It was a brilliant discovery founded on acute penetration and sound reasoning. It was, moreover, a discovery that the public were able to appreciate, and by popular applause he was lifted at once into the front rank 
of astronomers. He was entitled to all the renown which he acquired. For though others may have entertained similar views and expressed them more or less distinctly, they fell short of demonstration. Prof. Kirkwood, for example, had put the pertinent question, "May not our periodic meteors be the débris of ancient but now disintegrated comets, whose matter has become distributed around their orbits?" At a moment when we are remembering with gratitude the eminent services of the distinguished Italian astronomer, there is no necessity to stir old controversies; but when so many, from the time of Halley, have been so near a solution of the puzzle, it may quicken our appreciation of his genius to remember that he carried the question one step beyond his predecessors, removing it from the grounds of conjecture to the certainty of conviction. In this connection it is not out of place to recall the remarkable series of letters that Schiaparelli addressed to Father Secchi in 1866, models of close reasoning leading to a successful result. But as is frequently the case when a brilliant discovery is made, it is possible to detect a certain amount of luck contributing to the final outcome.

Schiaparelli's crowning success was the recognition of the similarity of the orbit of the August meteors with that of the comet of I862. That this particular comet of long period should have returned to the sun only a few years previously to the discovery, and that its path had been well determined, was a most fortunate circumstance, and one that not only strengthened the evidence of identification, but affected the popular estimate of the certainty of the result. Similarly, with the near coincidence of the return of the comet of 1866 with the great November shower, and less conspicuously that of the 186I comet with the April Lyrids, astronomers had the advantage of dealing with trustworthy elements. If these comets had passed through perihelion without being observed an important link would have been wanting in the chain of evidence. As it is, these earliest cases of identification are the most conspicuous and the surest examples of a relation, as significant as it was unexpected. For his part in the happy result Schiaparelli was deservedly awarded the gold medal of the Royal Astronomical Society in 1872 .

In some other directions the work of Schiaparelli has not received the same complete recognition. In 1877, when Mars was in a favourable position for observation, he announced the detection of the famous canals which have since been the subject of fierce dispute and controversy. Whether these "canals," interrupting the continental areas, are existent and permanent phenomena has been much questioned; though the doubts expressed do not relate so much to the existence as to the interpretation that has been placed upon them. Schiaparelli regarded the "gemination" of the canals as a periodical phenomenon depending on the seasons, and was firmly convinced of their alternate obliteration and reappearance. The only point on which we need insist here is the effect that his industry and acuteness of vision have had on the development of astronomical observation. It has been the means of attracting a vast amount of attention to the planet, has enormously increased the activity of observation, and led to the training of a class of observers, who have taken up the subject of planetary markings with avidity. Schiaparelli has written much on the appearance of Mars, and a very large literature has collected round this subject, due largely to his initiative.

Another subject with which his name will be connected is the attempt to derive the times of rotation of Mercury and Venus. Our information on this topic is vague, and the data uncertain. Notwithstanding the care bestowed on the observations, and the plausible nature of his deductions, his results have been accepted with some hesitation. From his patient watching, and from the length of time devoted to the study, his conclusion that Mercury turns on its axis in the same time that it revolves round the sun is entitled to very great consideration. 'This result was published in 1882 , and it was not until some years later, 1890 , that he declared that Venus behaver in a similar manner to Mercury. The long interval showed that Schiaparelli did not jump to conclusions, and the limits he assigned to the rotation, between six and nine months, prove that he was not inclined to accept a hypothesis, however specious, in favour of the results of observation.

These three conclusions, having reference to the connection of meteors with comets, to the surface markings of Mars, and to the velocity of rotation of the interior planets, are no small achievement in the life of one astronomer. It need not be said that they do not exhaust his scientific activity. A vast amount of routine work, of double-star measurement, and of the position of planets, stands to his credit. He was the author of some 250 papers in various journals and his memory is as much entitled to our respectful homage for his industry as for his originality.

W. E. P.

\section{PROF. J. G. GALLE.}

$\mathrm{W}^{\text {ITH }}$ deep regret we have to announce the death, on July ro, at ninety-eight years of age, of the veteran astronomer Prof. J. G. Galle, the doyen of the Associates of the Royal Astronomical Society, into which body he was elected in 1848 . For many years he had been connected with the Berlin Observatory, and will be remembered as the last of the little band of astronomers who were associated in the discovery of Neptune. Galle it was who had the good fortune to carry to complete fruition the successful analyses of Adams and of Le Verrier. It was his lucky chance to compare Bremiker's map with the sky, to detect the planet, and establish its identity by determining the motion. He long outlived all his companions and associates in that historic scene enacted in the Berlin Observatory on September 23, 1846, the antecedents of which have been told so many times that it is unnecessary to refer to them here more particularly. It is more pertinent to recall, as more likely to have been forgotten, that he was one of the first to have seen the "crape" ring of Saturn. When this discovery was announced in 1850 , simultaneously by Bond and Dawes, Galle directed attention to some observations he had made twelve years earlier, in $1838-9$, in which he had actually measured the diameter of this interior dusky ring. The observations were communicated at the time to the Berlin Academy, but Galle did not insist on their importance, as he could not persuade himself that the phenomenon was permanent and not due to the effect of contrast.

From Berlin, Galle went to Breslau, and there he proposed that method of determining the solar parallax, by observations of small planets, which has since proved so successful. His earliest attempts in this direction were applied to measures of Phocaea, and later, from observations of Flora, he deduced the value of $8 \cdot 87^{\prime \prime}$. This was at a time when astronomers were beginning to discard Encke's value of $8.5^{\prime \prime}$ in favour of Le Verrier's $8^{\circ} 95^{\prime \prime}$. In another direction it is not possible to overlook a very distinct service which Galle rendered to astronomy. His catalogue of cometary orbits has long been a standard work 